
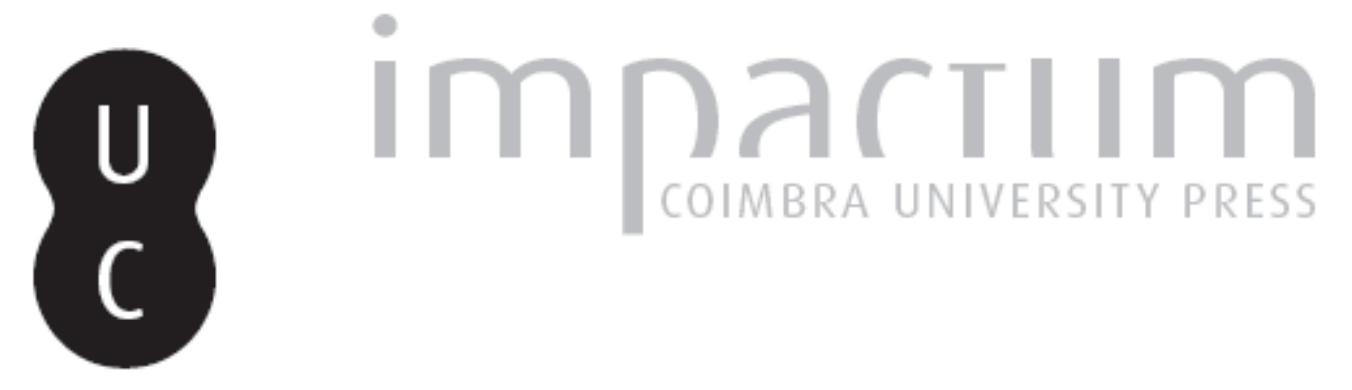

\title{
Mujer y poder en Irán contemporáneo
}

\section{Autor(es): Merinero, María Jesús}

Publicado por: Faculdade de Letras da Universidade de Coimbra

URL persistente:

URI:http://hdl.handle.net/10316.2/39982

DOI:

DOI:https://doi.org/10.14195/0870-4112_2_14

Accessed : $\quad$ 26-Apr-2023 13:57:54

A navegação consulta e descarregamento dos títulos inseridos nas Bibliotecas Digitais UC Digitalis, UC Pombalina e UC Impactum, pressupõem a aceitação plena e sem reservas dos Termos e Condições de Uso destas Bibliotecas Digitais, disponíveis em https://digitalis.uc.pt/pt-pt/termos.

Conforme exposto nos referidos Termos e Condições de Uso, o descarregamento de títulos de acesso restrito requer uma licença válida de autorização devendo o utilizador aceder ao(s) documento(s) a partir de um endereço de IP da instituição detentora da supramencionada licença.

Ao utilizador é apenas permitido o descarregamento para uso pessoal, pelo que o emprego do(s) título(s) descarregado(s) para outro fim, designadamente comercial, carece de autorização do respetivo autor ou editor da obra.

Na medida em que todas as obras da UC Digitalis se encontram protegidas pelo Código do Direito de Autor e Direitos Conexos e demais legislação aplicável, toda a cópia, parcial ou total, deste documento, nos casos em que é legalmente admitida, deverá conter ou fazer-se acompanhar por este aviso.

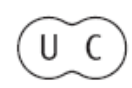


REVISTA DA FACULDADE DE LETRAS U N I VERS I A D E D E C O I M B RA 


\begin{abstract}
:
Can one strictly speak of democracy if the political power does not address the problems, needs, interests and demands of at least half of the population formed by women and does not put an end to their exclusion from the different social fields?

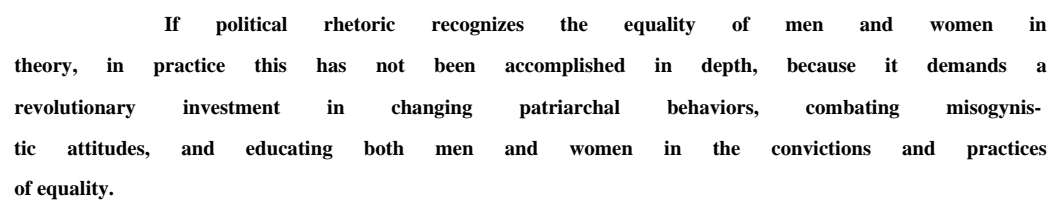

It is interesting to consider the historical process of the Islamic Republic of Iran, where women have not only become a fundamental factor in the transformation of their own situation, but also in the establishment of the process of modernization of the socio-political life. Pioneers in the Muslim world, they
\end{abstract} present effective formulas for the feminist movements of all countries.

Introducción

¿Es riguroso hablar de democracia si el poder político no atiende los problemas, necesidades, intereses y demandas de la mitad de la población, formada por mujeres y no acaba con su exclusión en los diferentes campos sociales?

Sin embargo, la realidad confirma que la mayoría de los países que se consideran avanzados y que teóricamente reconocen la necesidad de promover la igualdad entre hombres y mujeres, no lo llevan a cabo en profundidad porque para ello hay que invertir en cambiar no sólo gestos, sino comportamientos muy arraigados que exigen una gran inversión destinada a educar en convicciones y prácticas de igualdad, tanto a hombres como a mujeres; especialmente a aquellos, que practican la exclusión de éstas, y a éstas para que conozcan y ejerzan sus derechos.

Es necesario conocer un poco de historia política de diversos lugares de nuestro planeta para ser capaces de medir la contribución de las mujeres en el campo de la política y la vida social. 
Las mujeres contribuyen, como protagonistas, en la resolución en zonas de conflicto. Anne Gahongayire, viceministra de la Mujer en Ruanda, país que ha sufrido uno de los genocidios más brutales en los años 90 , y en el que las mujeres representan hoy el $74 \%$ de los escaños del Parlamento, muestra cómo han sido las mujeres las que han logrado hacer entender a todos que la reconciliación entre hutus y tutsis sólo era viable si se incorporaba activamente a las mujeres en las negociaciones. Porque las mujeres tienen mayor capacidad y disposición a cooperar de forma transversal, entre distintos grupos, partidos, ideologías.

Según el director de la División for the Advance of Women de la ONU, las mujeres, al ser menos propensas a la corrupción, pueden colabor ar a corregir uno de los vicios más frecuentes que afectan al poder.

Por su parte, el informe de Naciones Unidas sobre desarrollo humano (PNUD) de 2002, señalaba la marginación femenina como una de las tres causas del atraso de muchos de los países árabes. Por ejemplo, en Kuwait, la ley electoral de 1962 establece el derecho a voto y a ser candidato en las elecciones para los hombres mayores de veintiún años; de tal forma que en las últimas elecciones legislativas que se celebraron en 2003, sólo pudieron votar 136.000 hombres de entre una población de

910.000 kuwaitíes. Las kuwaitíes pueden llevar minifalda y no ir veladas, pero no pueden votar.

Por eso nos parece importante detenernos en el caso de la República islámica de Irán, donde las mujeres han conseguido convertirse en un factor fundamental en el proceso de modernización de la vida socio-política, pioneras en el mundo musulmán y modelo para los movimientos feministas de otros países, y no únicamente musulmanes.

\section{Dimensión antropológica y política de la mujer musulmana}

La confusión generada en Occidente en torno al fenómeno islamista, mantiene el entusiasmo en los medios de comunicación por el tema de las mujeres musulmanas, reduciendo la consideración de las mujeres a una vertiente sexista ${ }^{1}$. Soterrando su papel como agentes de múltiples campos de relaciones sociales, se olvida la renovación ideológica que encierran sus discursos y sus prácticas.

La situación de la mujer en los países islámicos es susceptible de ser analizada desde diversos campos entre los que tiene preeminencia 
el de su situación jurídica. Y esta dimensión implica el análisis de la relación que existe entre mujer y democracia y su participación en el desarrollo de sus respectivos países.

No en todos los países musulmanes la problemática femenina se plantea de la misma forma. De ahí que la iraní Shahla Sherkat hable de un feminismo autóctono.

La consideración social de las mujeres hay que analizarla inserta en una doble dinámica: su dimensión antropológica, considerando la estructura patriarcal dominante en la sociedad iraní, que debe ser completada con su dimensión política ${ }^{2}$, ya que tanto el discurso como la praxis del movimiento feminista iraní representa uno de los campos en los que se opera la más clara articulación de las nuevas reivindicaciones de la sociedad civil frente al Estado y frente a la institución religiosa.

El análisis desde esta doble perspectiva despoja la consideración teórica sobre el estatuto jurídico de la mujer de cualquier consideración ideológica 0 culturalista y obliga al estudioso a abandonar consideraciones simplistas y a desvelar su papel activo en las relaciones sociales.

Esta metodología proporciona la oportunidad de aproximarse más a la realidad del movimiento feminista iraní que, progresivamente, ha ido adquiriendo una dimensión más compleja, permitiendo que en su seno confluyan diversas generaciones con procedencias sociales distintas, que portan referencias culturales e ideológicas muy variadas. Encontraremos que en él conviven islamistas y laicas, conservadoras y modernas, tradicionalistas y vanguardistas. Diversidad de referencias que se muestran en sus argumentos acordes con las perspectivas socio-politicas y culturales de cada una de sus protagonistas.

$\mathrm{Ni}$ todas las mujeres van a optar por las mismas fórmulas, ni el proceso es uniforme ni sincrónico en todo el mundo musulmán.

En el centro del debate sobre la situación de la mujer en el mundo musulmán debe situarse una cuestión básica : la sacralización del orden patriarcal mediante el vínculo que se ha establecido entre islam e identidad cultural, representado por la familia musulmana. El patriarcado es una forma de organización social dominante en todo el Mediterráneo que se ha encarnado a lo largo de la historia en sociedades que si distintas entre sí, en todas se ha mantenido un principio central: que los hombres deben dominar a las mujeres.

\footnotetext{
2 M. J. Merinero, iraníes modernas' in M. J. Merinero, Irán. Hacia un desorden prometedor (Madrid, Los Libros de la Catarata 2001) 196.
} 
En el mundo musulmán, cuando el islam concedió a la mujer el derecho a la herencia, se desató el miedo a perder el patrimonio familiar, y como reacción se normalizará la práctica de casar a las hijas con los primos por vía paterna. La obsesión de preservar la pureza de la sangre (la cuestión del "honor" familiar) hará que se procure casar a las hijas dentro del clan. De este modo se perpetua la institución patriarcal, y el matrimonio se considera tradicionalmente como un asunto de familia, comunitario y social, no individual, puesto que está concebido como un mecanismo para la reproducción, para el refuerzo de lazos e intereses familiares y para la preservación de la propiedad a través de la herencia, en beneficio de los intereses comunales. La institucionalización del " mahr"- dote que el hombre debe obligatoriamente dar a la mujer para contrarrestar el matrimonio, y para la manutención de la esposa - exige, en contrapartida, la correspondencia de la esposa reconociéndole su autoridad y mostrándole obediencia, colocando así a la mujer bajo la protección económica y la dependencia del marido, y estableciendo una separación entre el espacio público y el doméstico, obstaculizando el acceso de la mujer al mundo del trabajo.

La aplicación del sistema jurídico islámico (fiqh) en el ámbito familiar, fue el instrumento que ha servido en gran parte del mundo musulmán para perpetuar un modelo de sociedad patriarcal y patrilineal mediante una conservadora interpretación de la sociedad, volcada en unos Códigos de la Familia en los que se consagra, aunque con diferencias entre unos países islámicos y otros, el principio de autoridad del hombre sobre la mujer. Leyes sobre la familia, en muchos casos, como en Argelia, Túnez y otros países árabes, aprobados por élites políticas occidentalizadas, en búsqueda de legitimidad islámica, para garantizarse el monopolio del uso político del islam ${ }^{3}$, institucionalizaron una interpretación oficial del islam al que concedieron la gestión ultraconservadora de la sociedad musulmana.

No obstante, dentro del mundo islámico, la conciencia del obstáculo al progreso social que suponía la estructura social patriarcal, fue un elemento de crítica presente en el movimiento de renovación y de reforma de la salafiyya, dentro del cual surgen las primeras voces que defienden la liberación de ia mujer. Sus defensores, intelectuales musulmanes cercanos al pensamiento ilustrado europeo abogan por la liberación de la mujer y la igualdad entre los sexos. Entre ellos Muhammad Abduh

3 S. Naïr, En el nombre de Dios (Barcelona, Edit. Icaria 1995). 
(1849 - 1905) que fue el primero que hizo suya la reivindicación, hasta entonces impensable de la emancipación de la mujer musulmana, al considerar que mantener su postergación impedía cualquier progreso social. Demostrando, mediante su exégesis ${ }^{4}$ del Corán, que el islam no sólo no se oponía a la evolución femenina sino que otorgaba a la mujer derechos como ser independiente e igual al hombre.

Fueron estos reformadores, pioneros del islamismo y, en muchos casos, fuente de inspiración para los movimientos islamistas contemporáneos quienes, con sus escritos, consiguieron abrir la polémica que será continuada por todos los movimientos reformistas, e influirán posteriormente en las feministas.

El movimiento feminista iraní responde a cambios sociológicos que han hecho posible una toma de conciencia de la diferencia creciente entre el derecho y el puesto de las mujeres en la sociedad, por una parte; y entre la evolución de las costumbres y el conservadurismo de las normas sociales y culturales establecidas por el régimen, por otra.

La mujer está presente de forma activa en toda la escala profesional, desde las abogadas a las tecnócratas, pasando por quienes trabajan en las administraciones y en el sector salarial. La influencia de las tecnócratas, al aportar su consideración sobre los cambios económicos y sociales, que han transformado la sociedad iraní, dotan al movimiento feminista de una visión más moderna y pragmática 5 .

Las mujeres iraníes representan el $20 \%$ de la población activa, sin contabilizar el trabajo rural, pero irá en aumento a medida que las nuevas generaciones de jóvenes instruidas se incorporen al mercado de trabajo, pues han sabido sacar provecho de la política de alfabetización masiva puesta en práctica después de la revolución sobre todo en las zonas rurales, marginadas durante el régimen anterior. Hoy, el porcentaje de las escolarizadas ${ }^{6}$ se acerca al de los varones, más del $80 \%$. En la Universidad constituyen el 40\%, y en 1998 el número de admitidas al concurso nacional de ingreso superó por primera vez al de varones. En el año 2000 representaron el 58\% de los aprobados. El alza en el nivel educativo

\footnotetext{
G. Martin Muñoz: "La igualdad entre los sexos y la cuestión de los derechos humanos y del ciudadano en el mundo árabe" in G. Martin Muñoz (comp.) Mujeres, democracia y desarrollo en el Magre b (Madrid, Edit. Pablo Iglesias 1995) 3.

5 Su visión de la realidad ha levantado las iras de las mujeres "hezbolla" que las recriminan su occidentalización y liberalismo. Para una discusión sobre las mujeres tecnócratas, ver A. Kian_Thiebaut, Women and Politics in 'Post-Islamist Iran: the Gender Conscious Drive to Change' in British Journal of Middle Eastern Studies 24 ( 1 ) 1997.
}

6 'EI Correo de la Unesco' (junio 2000). 
ha favorecido su autonomía. Además, el número de muchachas en los consejos estudiantiles no ha dejado de aumentar. La estructura social descansa en las mujeres.

Más de cuarenta editoriales tienen una dirección femenina y publican libros que conciernen a las mujeres 0 son escritos por ellas. La profesora Shala Lahidji creó en los años ochenta, su propia casa editorial con el único objetivo de publicar libros sobre las mujeres: "Al principio no era fácil, y el primer año, en 1983, no he podido publicar más que un libro7. Después, más de un centenar, especialmente obras sobre las condiciones de las mujeres en Irán, el trabajo femenino, los derechos de las mujeres, la mujer en el cine iraní; pero también poesías escritas por mujeres iraníes que intentamos que se conozcan con amplitud. A la vez que hemos publicado numerosas traducciones como "El libro de la risa y el olvido" de Milan Kundera, Las "novelas orientales" de Marguerite Yourcenar o "Cartas a Olga" de Vaclav Havel.

$\mathrm{Su}$ presencia en la producción y dirección cinematográfica como la productora Dans Sara, o las directoras Samina Majmalbaf y Rakhshan Bani Etemade, que han alcanzado galardones internacionales son una pequeña muestra de la presencia activa y comprometida de las mujeres en la vida pública.

A lo largo de los veinticinco años de existencia de la república islámica, el movimiento irá atravesando diferentes etapas desde la inicial movilización femenina en los años de la revolución, hasta desembocar en la reestructuración de un movimiento propiamente feminista.

Consecuentemente el análisis del discurso "feminista" bajo la República islámica no es fácil porque es, a la vez, complejo, singular y paradójico, al menos en apariencia. Como todos los discursos que giran en torno a las relaciones sociales, no puede ser reducido a su única expresión formal ni a la identidad de sus actrices y representantes 8 , lo que obliga a buscar sus orígenes en el contexto social e ideológico que precede a su emergencia y a escudriñar las estrategias de sus militantes así como las orientaciones del movimiento social que las anima. De hecho, la actitud de las mujeres iraníes ha atravesado diferentes etapas desde la inicial movilización femenina que acompañó a la revolución, hasta desembocar en la reestructuración de un movimiento propiamente feminista a comienzos de los años noventa.

\footnotetext{
S. Ghazi, Iran: des voix sous les voiles' in Vivre Autrement, n. ${ }^{\circ} 2$ - 1 sept (1993).

N. Yavari-d Hellencourt, (dir). Les femmes en Iran,pressions sociales et stratégies identitaires (Paris, L'Harmattan 1998).
} 
Para todas las mujeres, el objetivo es acabar con un modelo de sociedad patriarcal y jerarquizado, consagrado mediante una interpretación de la ley religiosa, en la que se perpetua el principio de autoridad del hombre sobre la mujer. Las mujeres deben movilizarse tanto en la sociedad como en familia y en un doble frente contra el autoritarismo a la vez que contra el sexismo.

\section{Mujer y revolución.}

Al final de los años 70 , después de medio siglo de modernización autoritaria en Irán, la emancipación de la mujer no había calado en los medios tradicionales. Las reformas ${ }^{9}$ introducidas por el Sha mediante la "revolución blanca" habían constituido importantes avances hacia una mejora de la situación jurídica de las mujeres, pero no habían tenido un efecto significativo. Las mujeres instruidas y modernas fueron las que se beneficiaron, pero las de medios tradicionales se quedaron al margen de ellas, en cuanto que las referencias culturales en las que se asentaban les eran extrañas y aparecían como contradictorias con las suyas, sintiéndolas como una amenaza a la "identidad islámica".

Por otra parte, esta legislación, establecida por un régimen cada vez más impopular y percibida como una imposición de Estados Unidos, fue boicoteada por la oposición, y no tuvo más que un impacto limitado sobre la sociedad civil.

Será la activa participación de las mujeres en la revolución de 1979, el verdadero punto de arranque para el desarrollo de la movilización femenina en la vida pública.

No se debe olvidar que la toma de conciencia de los derechos de la mujer islamista se debe, en gran parte, a las conquistas de la revolución. Los discursos del Imán Jomeini hacen hincapié en el derecho de las mujeres a participar en política, y a interesarse por los asuntos esenciales de su país. La reislamización de la sociedad tras la caída del Shah y la insistencia del imam Jomeini en la legitimidad de la presencia de las mujeres en la escena social y política ${ }^{10}$ redujo la resistencia de las familias tradicionales a dejar a sus hijas circular libremente en el espacio público, a la vez que las mujeres procedentes de los medios populares

9 Véase M. H. Malek, The Political Economy of Iran under the Shah (Londres, Croom Helms 1986); Berhang, Iran, le maillon faible (CHEAM 1979).

10 Véase F. Adelkhan, La revolución bajo el velo (Barcelona, Edit. Bellaterra 1996) 76 y ss. 
encontraron en la revolución islámica una forma de acceso a la vida política.

De ahí que algunas mujeres islamistas hagan referencia a su adhesión a las ideas de Jomeini, pues la revolución, al poner a la mujer en el centro de la sociedad, facilitó involuntariamente la creación de un campo específico femenino.

En favor de un islam activo, el Guía promueve y autoriza esta feminidad ${ }^{11}$ al reclamar en su nombre la ruptura con las viejas normas; a partir de entonces la emancipación de las mujeres se reclamará en nombre del islam, a diferencia del Antiguo Régimen que se enunciaba en nombre de una modernidad anti-islámica.

Las mujeres cambiarán el registro de su discurso acomodándole al lenguaje ideológico de los gobernantes, y expresarán sus reivindicaciones desde las referencias islámicas.

De tal forma que la contestación masiva de las mujeres adoptará unas estrategias concretas, situando las leyes discriminatorias en el marco de las relaciones sociales, argumentando a través de los preceptos religiosos, de tal forma que tanto sus discursos como su praxis son abordados a través del filtro del islam.

Desde el comienzo de la revolución la mujer participó activamente en asambleas exclusivamente femeninas que dieron la palabra a los dirigentes políticos; y con sus acciones, las mujeres les obligaron a tomar iniciativas que les fueran favorables. La extensión de un número significativo de publicaciones dirigidas a las mujeres desde el triunfo revolucionario, tenía como objetivo demostrar que las mujeres estaban integradas en la base social del régimen.

En la Constitución de la República islámica de Irán se afirman principios universales de igualdad sin discriminación de sexo, raza 0 religión, en pro de una visión de los individuos como ciudadanos, inspirados en el derecho positivo y el principio 20 la igualdad de los sexos en el respeto de los principios islámicos.

Frente a esto, la dimensión islámica de la sociedad se encuentra regida por la religión que es la que determina la pertenencia a una misma comunidad cultural- religiosa. Y en este nivel la "comunidad" prevalece sobre el individuo, y la sociedad se organiza en función de esta pertenencia cultural-religiosa. Acorde con esta consider ación se produce la incor- ${ }^{*} 48$

48 -49 (1989).

Faculdade de Letras | Universidade de Coimbra 
poración de la sharía al sistema jurídico ${ }^{12}$, lo que no impide la existencia de un espacio privado libre.

En la introducción de la Constitución de 1979, se plantean los derechos de las mujeres iraníes en el marco de los derechos humanos. Y aunque la familia aparece diseñada como la unidad fundamental de la sociedad y el marco principal de su desarrollo, el apartado constitucional presenta una tendencia a favorecer otros aspectos de la vida de la mujer, que superan su ámbito familiar: "Gracias a los fundamentos islámicos de la sociedad, los hombres que hasta ahora ponían sus fuerzas al servicio de la explotación en todas sus formas, ahora recuperan su identidad fundamental y sus derechos. En este sentido, es natural que se favorezca a las mujeres y que puedan acceder a más derechos, porque estaban sometidas a una represión más fuerte por parte de "taqut" (en referencia al régimen del sha). La familia es la unidad fundamental de la sociedad y el corazón de la evolución y el progreso humano. (...) Uno de los deberes del gobierno islámico es, por lo tanto, garantizar las condiciones para la realización de este fin. Esta concepción de la familia es lo que permite a la mujer salir de una condición de “cosa ”, vinculada al consumo y a la explotación. Al tiempo que recupera su honroso y valioso deber de madre, ocupa una posición de vanguardia en la educación de los religiosos convencidos y participa al lado de los hombres en la vida activa; por consiguiente está habi litada para las más altas responsabilidades, y desde el punto de vista islámico, gozará de unas cualidades y una generosidad aún más importantes”^.

Paradójicamente la revolución islámica permitió mejorar la suerte de muchas mujeres salidas de medios modestos y tradicionales, a la vez que la propia revolución islámica se ha acompañado de toda una serie de medidas coercitivas respecto a las mujeres.

Al comienzo de la revolución las jóvenes, movilizadas en su favor, deben enfrentarse a un desafío político-ideológico importante, el riesgo de ser reducidas por los grupos tradicionalistas, a una feminidad "islámica" que las limitaría a ser generadoras y garantes morales de la integridad tradicional ${ }^{14}$. Es el inicio de un reto que acarreará una movilización y una estrategia complejas al menos, en dos frentes: Uno, correspondiente a las normas establecidas por el nuevo poder islámico; el

${ }^{1}$ L. Beck, y N. Keddie, (comps). Women in the muslim world (Cambridge, University Press 1978).

12 Citado por F. Adelkah, La revolución bajo el velo (Barcelona, Bellaterra 1996) 70.

14 F. Khoroskhavar, L'utopie sacrifiée. Sociologie de la révolution iranienne

(París, Presses de la Fondation Nationale des Sciences Politiques 1993) 121. 
otro, relativo a la génesis y conformación de una conciencia de sus pro pios intereses distintos e incluso opuestos a los de los hombres, que desemboque en reivindicaciones específicas de género.

La inicial movilización"islámica" de las mujeres será el ger men de su emancipación.

Pasada la etapa revolucionaria que unifica los objetivos de hombres y mujeres por el triunfo de la revolución, la relación entre los dos se problematiza y se politiza con la radicalización del movimiento rigorista "hezbollah" y las demandas de autonomía de la juventud feme nina revolucionaria. El proceso de individuación de los militantes revolu cionarios se acelera a medida que las mujeres multiplican las experiencias sociales.

Contrariamente a los que muchos habían creído, la mayoría de las mujeres no aspiraban a una simple sustitución de la autoridad paternal o marital por la del grupo de los hombres que las domina y controla invo cando al líder carismático. Progresivamente avanza la certeza entre muchas mujeres, mayoritariamente jóvenes, de que la nueva realidad social era inaceptable puesto que habían desafiado el orden patriarcal para obtener su autonomía y no para cambiar su sumisión.

La siguiente ruptura en el seno de la movilización de las muje res protagonistas de la revolución se produce tras la represión desatada por parte del "hezbollah"15, que se encargará de la vigilancia en la observación de una moral puritana, intentando en su función represora conseguir la legitimidad política del nuevo régimen.

La mujer hezbollah, portadora de una cultura tradicional, se empeña en marcar las diferencias entre hombre y mujer. Convencidas de ser las únicas portadoras de la verdad islámica se erigen en guardianas de esa convicción ejerciendo la función de defensa e imposición de su con cepción de la mujer ligada al honor de la comunidad $^{16}$, mediante la cual se sentirán legitimadas a apropiarse el campo político femenino.

15 "hezbollah" significa literalmente "partido de Dios". En el Irán revolucionario, "hezbollah" estuvo formado por grupos, generalmente de procedencia cultural tradicionalist que se pusieron al servicio de los intereses del grupo que se organizó en torno a Jomeini, como otras instituciones, estuvo destinado a eliminar toda oposición que impidiera poner e marcha el sistema concebido por el Imán.

16 F. Adelkah, 'Logique étatique et pratiques populates: la polysémie du hiyab chez les femmes islamiques en Iran' in Les Cahiers du CEMOTI, 10 (1990).

\section{Faculdade de Letras i Universidade de Coimbra}


La mujer "hezbollah" se convertirá en un aliado importante del estado represivo posrevolucionario. Estas mujeres, que forman un grupo ideológico muy activista, se afilian al grupo "jomeinista ${ }^{\mathrm{M}}$ bien para conse guir ascenso social, esperando verse aceptadas como las únicas mujeres islamistas legitimadas para intervenir en el campo de la política ${ }^{17}$ a cam bio de sus servicios a los gobernantes, bien como medio de lucha contra la depravación y contra Occidente, representado por lo que ellas conside ran "antiislámico".

La concepción intolerante de la mujer defendida y promovida por las mujeres "hezbollah", se fija esencialmente en el cumplimiento estricto de las normas que afectan a la moral pública, las relaciones entre hombre y mujer, $y$ en la obligatoriedad de guardar una imagen externa puritana (cubrirse con el chador, negación de cualquier signo externo que pueda interpretarse como atentado al recato femenino, prohibición de relacionarse en público con hombres que no pertenezcan por línea directa a la familia, etc).

Por el contrario, para la mujer islamista no "hezbollah", las preocupaciones se centran en la degradación del nivel de vida, la infla ción, o el caos generalizado.

$\mathrm{Si}$ en el inicio de la revolución, el uso del "hiyab" significó la afirmación de la nueva sociedad frente al régimen imperial, y en algunos sectores supuso un símbolo frente a la occidentalización, el velo repre senta el mantenimiento del honor comunitario; pero, en su dimensión polisémica $^{18}$, el "hiyab" se convierte en el pasaporte de las mujeres para entrar en el mundo exterior. La adopción del "hiyab" frente al chador tra dicional significa para estas mujeres islamistas, el rechazo de formas anti guas y la afirmación de una autonomía cultural. Por lo que la adopción del hiyab no debe entenderse como símbolo de una transmisión tradicio nal de las normas religiosas sino como símbolo de una reapropiación del islam como identidad cultural.

Conscientes de que la libertad y el progreso de las mujeres no reside en el tamaño del velo sino en el acceso, en igualdad de condiciones que el hombre, al trabajo $y$ a las restantes funciones, muchas mujeres islamistas han adoptado, de buen grado, el hiyab que las permite estar activas y presentes en la vida pública.

17 F. Khoroskhavar, L'Utopie sacrifiée. Sociologie de la revolution iranienne

(Paris, Presses de la Fondation Nationale des Scienees Politiques 1993$) 133$.

18 F. Adelkah, 'Lógique étatique et pratiques populates: la polysemie du hiyab

chez les femmes islamiques en Iran' in Les Cahiers du CEMOTl, 10 (1990).

\section{Faculdade de Letras i Universidade de Coimbra}


La imposición del uso del "hiyab" en la forma de vestir que acompañó a las depuraciones de funcionarios en las administraciones, se convierte en norma oficial ${ }^{19}$ a partir del verano de 1980; respondiendo a este objetivo se impuso el hiyab como elemento obligatorio para trabajar. El propio imam Jomeini publicó un decreto religioso (fatwa) para confir mar que respetando el "hiyab", las jóvenes tenían el derecho de frecuentar las universidades $y$ ejercer un trabajo fuera del hogar. Incluso cuando los padres se oponían al ejercicio de esta libertad postrevolucionaria, un número creciente de mujeres y de jóvenes no dudaban, en nombre del islam y la revolución, en afrontar o desafiar al padre, hermano o marido para entrar en este "nuevo mundo": la sociedad, la calle, la universidad, el trabajo, las asociaciones militantes.

Si la imposición de la ley islámica supuso un retroceso para las mujeres procedentes de las clases altas más occidentalizadas de la época imperial, la obligación de llevar el vestido islámico y la relativa separa ción del espacio de trabajo y de formación entre sexos, han constituido elementos de peso que han animado a las jóvenes de familias tradiciona les, socializadas en una identidad comunitaria y patriarcal, a estar pre sentes en el espacio público.

La socialización posrevolucionaria de las jóvenes y de las mujeres de ámbitos tradicionales, de las clases populares y de la clase media le permite acceder al status de "sujeto" autónomo respecto a sus familias y grupos de pertenencia ${ }^{20}$. Su nuevo puesto en la sociedad, soporte de su identidad social ${ }^{21}$ había sido legitimado y sacralizado por la revolución islámica y su Guía.

El paso del espacio privado al espacio público, de la defensa identitaria a la acción colectiva y a la solidaridad nacional, no se efectúa sin que entrañe profundos cambios.

Después de la fase unanimista del periodo revolucionario, los acontecimientos posteriores -crisis de los rehenes americanos y especial mente la guerra con Irak- pusieron de manifiesto la ambigüedad del dis

$-49,(1989)$.

19 F. Khoroskhavar, 'Le mouvement féminin en Iran', Peuples mediterranéens 48-

20 C. Dubat, La socialisation. Construction des identités sociales et profess-

sionnelles (París, A. Colín 1991).

21 Véase A. Kian, 'La formation dime identité social feminine dans I Iran post-révolutionnaire: un enjeu de pouvoir, in Yavari- d'Hellencourt (dir), Op. cit. (1998).

\section{Faculdade de Letras Universidade de Coimbra}


curso revolucionario, las contradicciones entre los actores políticos y las diferencias entre las fuerzas islámicas conservadoras y las reformistas ${ }^{22}$.

La aplicación arbitraria de las normas legales y las prácticas discriminatorias, observadas a lo largo del primer decenio posrevolucio nario funcionaron como catalizador en el movimiento latente de las muje res que, progresivamente se van a convertir en "grupos de presión".

El desprecio al apoyo incondicional que Jomeini presta a la actividad de la mujer hezbollah, será decisivo para que, incluso muchas jóvenes hezbollah, se autonomicen frente a las coacciones impuestas por el orden comunitario tradicional.

Al finalizar la guerra, se plantearon muchos problemas rela cionados con las familias de los muertos - viudas y madres - que pasaron a primer plano; a la vez que hicieron aflorar otros problemas como la tutela de los hijos de los mártires, arrebatados a su madres por la familia del marido para poder cobrar las pensiones otorgadas por la Fundación de los Mártires. Surgieron así muchas quejas de viudas que abrieron largas discusiones en el Parlamento; y en 1985 se aprobó una ley que otorgaba la tutela de un menor a la madre, a no ser que un tribunal rechazara su com petencia.

Desde el final de los años setenta, la relación dialéctica entre contestación femenina y élites políticas, irá dando lugar a modifica ciones, tímidamente perceptibles, en la legislación referida a los asuntos femeninos.

Al finalizar la guerra, y con el inicio de la presidencia de Rafsanyani, en 1989, se inaugura una nueva etapa en las relaciones de las mujeres con el poder. Es este un periodo en que el papel económico de la mujer adquiere significado, debido al inicio de una etapa de reconstruc ción económica que sucede a una economía de guerra. El programa eco nómico del gobierno centrado en el objetivo de "crecimiento económico equilibrado y desarrollo social", va a verse acompañado por un nuevo discurso del poder que se refiere a las mujeres como a "agentes del desar rollo" e "invalorables recursos humanos", a la par que se mantienen limi taciones a su progreso cerrándola el paso en diferentes especialidades. En nombre de un desarrollo más equilibrado se adoptan medidas de control de la natalidad, que tenía una tasa del 3,7\% al año, acompañadas de la supresión de las ayudas o subsidios por número de hijos. 
Con el regreso de los jóvenes movilizados para la guerra, hay un intento de volver a recluir en el hogar a las mujeres. Paralelamente la represión se traslada del ámbito político al control de las costumbres. Las propias islamistas confirman que los derechos de las mujeres sufrieron un grave retroceso, que afecta incluso a las mujeres que mantienen su fe en el islam, que también han sido expulsadas de la esfera pública. "Las auto ridades no nos deseaban más que para manifestarnos en la calle chero $^{22}$ pero una vez acabada la revolución, quieren que regresemos al hogar. Me he dado cuenta que, a medida que la actividad social revolucionaria perdía su sentido, las mujeres perdian sus derechos. Desde esta constatación he comenzado a defender los derechos de las mujeres

La respuesta de las mujeres varió de acuerdo con su clase social y su ideología, y pasó del apoyo entusiasta a la revolución a la hos tilidad declarada.

\section{Feminismo postislamista y libertades públicas}

La paulatina cerrazón del régimen iraní, convirtiéndose en un estado ideológico, obstaculizaba el desarrollo de una sociedad civil que reflexionase $\mathrm{y}$ se pronunciase sobre importantes cuestiones, ha dado lugar, desde finales de los ochenta, al desarrollo de un intenso debate centrado sobre la relación entre Islam, Estado y democracia ${ }^{24}$, del que no están ausentes las mujeres.

El activismo de las mujeres en la vida social iraní tiene raíces seculares; sin embargo no se puede hablar de un movimiento plenamente feminista hasta comienzos de la década de 1990.

Instrumentalizadas por los poderes públicos, discriminadas a nivel económico y sometidas a grandes presiones por parte de las diversas tendencias ideológicas, las mujeres islamistas tratan de responder desarrollando movimientos asociativos creando canales de información, reivindicación, formación y movilización. Y a partir de los años 90 se desarrolla en Irán un movimiento especificamente feminista muy activo.

Los fracasos del régimen islámico para resolver los problemas sociales, le han conducido al desprestigio, a la vez que han conseguido $21 * * 24$

\footnotetext{
$1992)$ 41-43.

F1. Adelkah, 'Femmes islamiques, femmes modernes?', Pouvoirs 62 (otoño,

24 A. Kian-Thiébaut, Les Femmes ;raniermes entreF islam, $V$ État el le familie (París, Maisonneuve et Larose 2002).
}

\section{Faculdade de Letras | Universidade de Coimbra}


enajenarse el apoyo de gran parte de la sociedad. Desde los años noventa, una nueva generación de iraníes activos y movilizados confrontan sus ideas, replanteándose cuestiones claves de la vida de su país, tales como las relaciones entre islam y democracia, o el papel de las mujeres en la sociedad islámica.

Este grupo crítico con el poder, los postislamistas ${ }^{25}$, que incluye a las feministas iraníes, llevan a cabo una deslegitimación del régimen distanciándose de una revolución confiscada, e inician una reflexión sobre los problemas políticos, sociales y culturales de la socie dad iraní desde un análisis racional del islam ${ }^{26}$. Los diferentes resquicios que permite la estructura de poder en Irán, las medidas económicas liberalizadoras iniciadas por el presidente Rafsanyani, emparejadas con una mayor libertad de prensa, permitida por el régimen y alentada por el hoy presidente Jatamí cuando fuera Ministro de Cultura y Orientación islá mica, han facilitado, aunque no sin trabas y problemas, las expresiones femeninas. A la vez que la paulatina modernización de la sociedad iraní, que la ha acompañado, y una distensión en las relaciones exteriores de Irán - han sido otras razones estructurales, que han favorecido la toma de conciencia de las mujeres sobre sus derechos y su deseo de formar parte decisiva en el protagonismo de la sociedad civil postislamista que está conformándose en Irán.

Esta toma de conciencia, y la necesidad de no desperdiciar nin guno de los recursos humanos disponibles ha desembocado en la unión ${ }^{27}$ de mujeres laicas y mujeres islamistas para defender sus derechos, cons tituyendo un movimiento feminista muy activo.

El movimiento feminista iraní, muy activo, es pionero en el mundo musulmán donde, con frecuencia, y por razones históricas, muje res islamistas y mujeres laicas se miran con recelo cuando no se rehuyen ante la incapacidad de aunar sus puntos de vista, sobre todo acerca de las relaciones con el Estado. Si no abandonan ningún ámbito en el que recla mar y conquistar sus derechos, aprovecharán el terreno abonado por el

\footnotetext{
* Término utilizado por A. Bayat, 'The Coming of a Post-Islamist Society', in Critique (Autumn 1996).

26 M. J. Merinero, 'Les post-islamistes iraniens du soufisme a l'école de Francfort' in Cahiers cTétudes sur la Méditerranée oriéntale et le monde turco - iranien (París. Fondation Nationale des Sciences Politiques, n॰ 34, juillet - décembre. 2002 ). 
sistema jurídico vigente ${ }^{28}$ - tanto en el Código de Familia, como en la jurisdicción laboral femenina - para abrir un espacio no sólo de debate sino de actividad permanente que no descuida su aspiración a penetrar en las instituciones políticas como plataforma para propiciar las transforma ciones que exigen.

Más allá de las insatisfacciones de la sociedad civil frente al Estado, la participación social es la herramienta más eficaz del trabajo de la sociedad sobre ella misma. Si los iraníes aspiran a una plena democra cia islámica y a una sociedad civil islámica, esta aspiración pasa por la promoción de la emancipación de todos los ciudadanos.

Despreciando las presiones que pesan sobre ellas, las mujeres intervienen activamente en la vida social, científica, cultural y política; y como movimiento deben actuar en dos frentes: intentando cambiar el sis tema jurídico vigente y su aplicación arbitraria; y la más profunda y radi cal consistente en contribuir, a través de una intensa campaña social y cultural, a la evolución de la sociedad.

Las mujeres iraníes tienen un importante campo de acción, que sobrepasa el sistema jurídico, consistente en sensibilizar a la sociedad, no sólo sobre su situación de desigualdad, sino sobre las capacidades para participar en las transformaciones de su país.

Las islamistas recurrirán al islam para luchar contra un modelo de sociedad patriarcal que, según ellas, es fruto de una tradición anquilo sada que data de antes del Profeta y que se perpetúa desde entonces en nombre del islam.

Mujeres que forman parte de una nueva generación de islamistas, procedentes de la revolución, como las redactoras de la revista feminista "Farzaneh", Sra Ma'soumeh Ebtekar y Mamboubeh Ommi, ponen el acento sobre la distinción entre el islam y las tradiciones patriar cales sobre las que ciertos artículos de ley están fundados. Basadas en tal distinción reclaman a los religiosos reformistas que liberen los textos de estos artículos que ellas no juzgan auténticos. Intentan así adaptar la reli gión a una sociedad, en la que las mujeres participan activamente en la vida económica, social y política.

La militancia de las mujeres islamistas en este movimiento permite desarrollar una relación nueva de éstas con el islam y abrir bre chas en el orden patriarcal existente, con independencia de que esto con-

\section{Faculdade de Letras i Universidade de Coimbra}


cuerde o no con el ideario de los hombres islamistas ${ }^{29}$ que, como el resto de la sociedad, proceden de un sistema educativo y social patriarcal.

La socióloga Homa Zanyani-Zádéh aboga por la necesidad de buscar el origen de la institucionalización de las desigualdades en razones antropológicas $^{30}$, y mostrar que los cambios acaecidos en este ámbito, hacen irremediable su mutación: "El problema de las mujeres no es la desi gualdad con los hombres, sino la superioridad que se han arrogado los hombres institucionalizando las desigualdades. Hay que saber cómo se han institucionali zado las leyes para acabar con esta situación. Está claro que el sistema patriar cal se esfuerza por presentar este estado de hecho como natural y universal, para venir a decir que no se puede cambiar."

En la misma línea, la redactora jefe de la revista femenina "Zanan", Shahla Sherkat va más lejos y, en nombre de una lectura femi nista del islam, exige una reforma del pensamiento religioso ${ }^{31}$. "Cara a los problemas que afrontan las mujeres, un cambio radical de las leyes es necesario. Puesto que varios artículos del código civil están fundados sobre la sharía, la reinterpretación de estos es indispensable, y las mujeres deben participar en este esfuerzo".

Estos argumentos ponen de manifiesto que las tradiciones jurí dicas islámicas han estado siempre sujetas a la interpretación de los juris tas y a su acomodación a las realidades del momento. La capacidad del "faqih" para adaptar una ley a las realidades existentes ${ }^{32}$ pone de mani fiesto que el íytihad es imprescindible. El hecho de que los hombres, a quie nes se ha reservado el derecho a la interpretación no hayan favorecido a las mujeres, y sigan manteniendo una actitud misógina, es debido a que actúan en defensa de sus privilegios. De esta forma, a partir de razonamientos islámi cos, se denuncia el patriarcado de los jueces.

La inexistencia de organizaciones femeninas o feministas inde pendientes, puesto que las que existen de mujeres musulmanas, lo mismo que la organización islámica de las mujeres están, en realidad, ligadas al poder, no han conseguido hacerlas desistir.

\author{
y N. Yavari-d'Hellencourt, (dir) 'Les Femmes en Iran, pressions sociales et \\ strategies identitaires' (Paris, L'Harmattan 1998). \\ 30 Zanan, 4 de 1996. \\ 31 Declaraciones en "Zanan", y publicado por P. Vanrie, in 'Espace Orient' (1995). \\ 32 Ch. Chafiq, 'La femme et le retour de $F$ islam, $V$ experience iranienne' (París, \\ Editions du Felin 1991).
}

\title{
Faculdade de Letras Universidade de Coimbra
}


El auge del variado movimiento feminista en Irán y su presen cia en el espacio público, hizo que el Parlamento, redactara un proyecto de ley que tiende a prohibir " la defensa de las mujeres fuera de las nor mas legales", es decir, el feminismo ${ }^{33}$. Lo que las ha llevado a reagru parse en torno a publicaciones o revistas, donde expresan sus inquietudes y sensibilizan a la opinión pública y a la creación de una serie de revistas especificamente feministas como "Zan" y "Zanan". Una prensa dedicada a los temas de las mujeres ${ }^{34}$ existía ya, pero "Zanan" se inscribe en el con texto de la dinámica social en curso en la República islámica de Irán. Reagrupa en su seno a mujeres periodistas procedentes de diversos hori zontes; entre ellas se encuentran antiguas militantes revolucionarias que han evolucionado hacia una crítica de la interpretación esclerotizada de los preceptos del islam por las autoridades, sin por ello renegar del carác ter islámico del mensaje espiritual y social vehiculado por la revolución de 1979 .

Esta prensa ha dado la posibilidad de diálogo no sólo entre grupos con referencias religiosas distintas sino entre mujeres burguesas occidentalizadas y las procedentes de medios tradicionalistas o modestos.

"Zanan", fundada por Shahla Sherkat, una mujer islamista de la época de la revolución y durante mucho tiempo periodista del diario con servador "Kéan", del que fue despedida por sus posiciones feministas, es probablemente una de las pocas revistas feministas en el mundo. Hizo su aparición en 1992, con una tirada de más de 15.000 ejemplares, que se han multiplicado en la actualidad. Con tres periodistas permanentes y una red de 40 colaboradores/as, Zanan tira hoy 40.000 ejemplares y tiene unos 200.000 lectores. La venta de los ejemplares y la publicidad son las únicas vías de financiación. Su visión amplia de la función que debe desempeñar la revista se pone de manifiesto en la libertad de sus artículos, y en el humor. "Es importante para nosotros dirigirnos a un público amplio y no sólo a las intelectuales feministas de mi generación que tie nen tendencia a enredarse en debates teóricos. Es preciso llegar a los jóvenes". Su revista está abierta a millares de especialistas del derecho y sus columnas a todo el que piense.

48-49(1989).

F. Khosrokhavar, 'Le mouvement féminin en Iran', in Peuples mediterraneans

34 Véase $\mathrm{N}$. Yavari-d'Hellencourt, ' ${ }^{2}$ e feininisme post-islamiste en Iran', in Revue du Monde musulmán et de la Mediterrannée 85 -86 (1998); ○ la traducción del persa realizada por P. Vanrie del artículo 'La presse feminine' publicado en "Zanan", y publicado en Espace Orient (mayo 1998).

\section{Faculdade de Letras i Universidade de Coimbra}


La vocación decididamente feminista de su fundadora le lleva a no obviar ninguno de los temas que puedan afectar a las mujeres, desde las normas jurídicas al conocimiento del propio cuerpo.

Es la propia directora quien explica ${ }^{35}$ : "El feminismo ha sido siempre mi pasión. He tenido la suerte de estar apoyada por mujeres valientes que resistían como podían a la ley de los hombres". Más impor tante aún, hemos conseguido abatir la imagen del hombre dueño y señor absoluto de la casa y de los destinos familiares.

Percibe los cambios muy graduales, pero importantes, y cree que la revista ha contribuido a hacer que el feminismo no sea una palabra que suene mal en persa. Partidaria de tratar los temas que hablen de los asuntos cotidianos que afecten a las lectoras, recientemente la revista elaboró un dossier de las jóvenes que dejan la empresa familiar y se van a la calle.

Su pasión por la liberación de la mujer ha llevado a que "Zanan", en el contexto de la sociedad iraní, se haya convertido en una herramienta para que las mujeres tomen la palabra. $Y$ confiesa con satis facción: "Mi madre me dice frecuentemente que ella aprende a hablar leyendo la revista". $\mathrm{Y}$ es que para que las mujeres se hagan entender deben ser firmes y estar seguras de sus derechos. De lo contrario la causa no avanzará jamás”.

Zanan aborda de frente los tabúes. La revista se ha impuesto una regla, ser la primera en abordar los temas que enojan a la sociedad tradicional. ¿Por qué una mujer debe forzosamente casarse?, ¿por qué debe forzosamente convertirse en madre?, ¿por qué los hombres violentos deben quedarse con la custodia de sus hijos en caso de divorcio?. Los temas tabúes, como la sexualidad, también se abordan.

Dice Shahla "las mujeres son completamente ignorantes de sus cuerpos. Han sido formadas en la idea de que la mujer es un ser sin sexo. La mayor parte no conoce la existencia del clitoris. En estas condiciones las relacio nes sexuales son poco satisfactorias, tanto para la mujer como para el hombre La fuerza del tabú es tal que el único medio de evocar la cuestión es mediante artículos que utilicen de imágenes con doble sentido. Hemos tomado la delantera a la sociedad. El próximo mes publicaremos una entrevista con un sexólogo iraní.

Cada mes una periodista analiza una serie televisiva para poner al descubierto los mecanismos que denigran a la mujer haciendo de ella

35 Entrevista con Shahla Sherkat en "Le Temps du Monde”, año 2000. 
un personaje irritable y globalmente negativo. Pero los temas no se ago tan y se amplían desde la discusión política sobre las leyes discriminato rias, hasta la defensa de la mujer a practicar el deporte, respaldando así la iniciativa de Fáezed Hachemi, encargada de la promoción del deporte femenino, añadiendo la ventaja de ser una posibilidad de conocimiento entre los dos sexos.

Defensora de las conquistas y los éxitos de la revolución, no deja de reclamar un retorno a la libertad.

"El feminismo es siempre una cuestión tabú en Iran, donde se piensa que es el síntoma del rechazo total de los hombres ${ }^{36}$. Si se nos quiere tachar de feministas, no tenemos inconveniente. Pero esto sería un feminismo autóctono. Es cierto que nosotras tenemos reivindicaciones comunes con todas las mujeres del mundo, pero otras son específicas de las mujeres iraníes".

Shalha Sherkat, buena islamista, rechaza la idea de que el pro blema discriminatorio venga del islam, exponiendo una postura más con tundente ${ }^{3 \wedge}$. Lo que nosotros criticamos, sobre todo es a quienes en nombre del islam establecen discriminación con las mujeres. Personalmente creo que Dios, creando al hombre y a la mujer, no ha querido hacer discriminación entre ellos. Por desgracia muchos hombres piensan que las mujeres son por naturaleza infe riores. Pero tam bien muchas mujeres lo piensan, porque se han educado en esta idea. Ellas son aún más víctimas que las otras porque están totalmente alienadas. Esta desigualdad es la raíz de todo el mal.

Las feministas iraníes parten del principio de que son cons cientes de los problemas cotidianos del Irán moderno.

Las mujeres no están solas, muchos intelectuales post-islamistas defienden sus críticas, y apoyan sus reivindicaciones. M. Mohsen Saidzadeh, intelectual independiente, teólogo, ensayista, autor de diversos libros y $\operatorname{artículos}^{38}$ sobre la compatibilidad del Islam y la modernidad, especialmente sobre la discriminación de las mujeres en Irán, se ha situado a la cabeza de un movimiento popular para la reforma de la ley de la familia en Irán.

36 E. Rouleau, 'La Republique islamique <f Iran confronté á la societé civil', in Monde Diplomatique (juin 1999).

3^ L'Humanité, 26 mars, 1998.

38 Federación Internacional de Derechos Humanos, Ginebra/París, 1 julio 1998 . En noviembre de 1997, Saizadeh intervino en una conferencia organizada conjuntamente por la UNICEF y la Asociación Nacional de Protección de los Derechos del Niño, con base en Teherán, pero debido a su compromiso en la defensa de estos derechos, el 30 de junio 1998 ha sido arrestado en Teheran por agentes del ministerio de Información.

\section{Faculdade de Letras | Universidade de Coimbra}


Las mujeres postislamistas además defienden los derechos de las mujeres a acceder a los más altos puestos en la vida política ${ }^{39}$, pero sin poner en tela de juicio el sistema institucional de la República islá mica, como muestra la diputada Maziyeh Sadighi. Ellas proponen una reforma de las instituciones sin rechazar la herencia revolucionaria ${ }^{40}$ que fue benéfica para las mujeres en la participación en la vida de la ciudad. $\mathrm{Su}$ pragmatismo les lleva a eludir el enfrentamiento directo con el poder, lo que no quiere decir que cejen en su empeño.

Están seguras de encontrar un eco favorable entre los defenso res de una nueva interpretación de los textos sagrados que permita una mejora del estatus social y jurídico de la mujer, con el beneficio secunda rio de ver así realzada la imagen de la República islámica en el mundo.

Todos los discursos defienden los derechos de las mujeres en Iran utilizando este argumento hacia el que los hombres políticos se muestran sensibles. El discurso del Guía, ayatollah Jamenei, condenando violentamente a los talibanes afganos por su política discriminatoria con las mujeres se inscribe en esta línea. Denunciar la opresión de las mujeres afganas por los talibanes permite al Estado iraní resaltar su posición a favor de las mujeres y distanciarse de su imagen negativa en el dominio de los derechos de las mujeres.

Pero ellas no se contentan con ser "objeto de discurso" produ cido por los hombres, quieren formular ${ }^{41}$ ellas mismas sus reivindica ciones.

En parte, la lucha de las mujeres por sus derechos es parte de la lucha de la sociedad contra el estado ideológico, intentando lograr espa cios para todo tipo de organizaciones sociales y un marco legal en que los grupos organizados se sientan seguros para perseguir intereses particula res y respirar autonomía.

39 Para mayor extensión sobre este aspecto, véase M. J. Merinero, La República islámica de Irán. Dinámicas sociopolíticas y relevo de las élites (Madrid, Edit. Los Libros de la Catarata 2004).

40 M. J. Merinero, 'Mujer y democracia en la república islámica de Iran', in International Conference on Iranian Islamic revolution and future prospects (Teheran 2004).

41 A. Kian-Thiebaut, ${ }^{4} L^{\prime}$ emergence $d{ }^{\prime}$ un discours féminin indépendant en Iran post-islamiste: un enjeu politique', in Les Cahiers de /, Orient 47 (1998). 


\section{Sistema jurídico y contestación femenina}

A pesar de un discurso político elogioso para las mujeres, la modificación del sistema jurídico ha reforzado el poder, ya considerable, de los hombres en la familia. La autorización de la poligamia, la existen cia del divorcio en condiciones de gran desventaja para las mujeres, puesto que mientras que el hombre puede decidirlo unilateralmente, la mujer debe probar las faltas cometidas por el marido y previstas en la ley; o la preferencia que se le concede en la custodia de los hijos, de tal forma que los niños pueden ser custodiados por los padres a partir de los dos años, y las niñas a partir de los nueve años, lo muestran. La situación es igualmente discriminatoria en cuanto a la herencia y el testimonio, puesto que en ambos casos la mujer vale la mitad que un hombre.

Con el establecimiento de un nuevo sistema jurídico, las muje res han perdido sus derechos civiles, pero han conservado sus derechos políticos consecuencia de la convivencia de dos tipos de códigos jurídi cos, el positivo y el islámico, entre los que se producen serias contradic ciones e incoherencias.

A ello hay que añadir la desigualdad en ciertos derechos civi les. Existen funciones vetadas a las mujeres como ejercer la función de juez, o la prohibición de cursar ciertas ramas científicas, y sólo tienen derecho al $25 \%$ de las plazas disponibles para los estudios jurídicos. Si hay prohibiciones o limitaciones en la formación universitaria, éstas se escudan en un afán de equilibrio social, más que en normas islámicas. Por otra parte, las imprecisiones legales dan lugar a situaciones contra dictorias.

La desigualdad se extiende al ámbito penal ${ }^{42}$, puesto que una mujer es considerada mayor de edad para las cuestiones penales a los nueve años, mientras que un hombre no lo es hasta los quince; mientras que ambos tienen derecho a participar en el proceso electoral con derecho a voto, a partir de los quince años. La mujer puede casarse a los nueve años, pero no puede trabajar hasta los quince Desigualdades que se extienden al "precio de la sangre", prevista en la ley del talión (qesas) que se votó en el verano de 1982.

Existe pues una incoherencia en la diferente valoración jurídica de la mujer dependiendo de los ámbitos penal o político, y de la fijación

42 Artículo 1210, Ley civil de 1980, y Artículo 49 de la Ley penal islámica de 1990 .

\section{Faculdade de Letras | Universidade de Coimbra}


de una mayoría de edad política y otra jurídica. De tal forma que la mujer vale lo mismo que el hombre en el momento de la votación, pero la mitad que él en las cuestiones relacionadas con la herencia

En el ámbito de los derechos jurídicos es en el que las mujeres han actuado con mayor celeridad. Desde la primera legislatura posrevolu cionaria, las diputadas parlamentarias se encontraron desbordadas por las consultas, cartas, entrevistas y peticiones de mujeres que llegaban de todos los lugares exigiendo rectificaciones en el sistema jurídico y la equitativa aplicación de las leyes en el ámbito de los derechos de la familia.

Las restricciones impuestas a las mujeres en el campo de la formación y del empleo, provocará nuevas quejas. Y las quejas de profe soras y madres se han multiplicado contra la presentación sexista de la mujer en los nuevos manuales escolares ${ }^{43}$. El malestar generalizado ha encontrado canales de difusión, tanto en la prensa como a través de las diputadas en los debates parlamentarios. La retransmisión directa de las sesiones parlamentarias por la radio ha permitido a todas las mujeres, incluso a las que no leían los periódicos, constatar la amplitud de las desi gualdades entre sexos.

La ausencia de argumentación religiosa para estas nuevas dis criminaciones hizo tomar conciencia de la dimensión social de la domina ción que ejercen los hombres sobre las mujeres.

La prestigiosa jurista Shirin Ebádi, figura eminente del femi nismo jurídico en Irán, y Premio Nobel de la Paz en 2003, desde 1975 hasta 1979 fue la presidenta de los tribunales de la ciudad de Teheran pero tras la revolución islámica, al ser mujer, se le cambió de puesto en la administración y, en 1984, solicitó el retiro. Actualmente es abogada y enseña en la Universidad de Teherán. Ella señala la incoherencia existente en la diferente valoración jurídica de la mujer dependiendo de los ámbitos penal o político, y la de la fijación de una mayoría de edad política y otra jurídica, Pone así en evidencia las contradicciones entre una legislación moderna, aplicada al derecho al trabajo y al electoral, y una legislación de inspiración en el derecho tradicional islámico .Este razonamiento le per mite concluir ${ }^{44}$ que si el islam es unitario, coherente y homogéneo, las contradicciones en las leyes no se deben al islam, sino a los hombres que

\footnotetext{
43 N. Yavari-d'Heliencourt, (dir.) Op. cit. (París 1998).

44 Una consulta más amplia para estos aspectos: Ch. Chafiq y F. Khosrokhavar, Femmes sous le voile (París, Editions dii Félin 1995).
} 
al interpretarle pretenden mantener sus privilegios patriarcales en nombre del islam.

En segundo lugar, la argumentación se refiere a las tradiciones jurídicas islámicas, que siempre han estado sujetas a la interpretación de los juristas y a su acomodación a las realidades del momento. Esta capa cidad del "faqih" para adaptar una ley a las realidades existentes ${ }^{45}$ pone de manifiesto que el iytihad ${ }^{46}$ es imprescindible.

Existe una contradicción en la convivencia entre dos tipos de códigos jurídicos: el positivo y el islámico, estableciéndose una dicotomía político-religiosa difícil de armonizar entre la sociedad civil, regida por unas normas y la sociedad de los creyentes regida por otras; además de las graves contradicciones entre las convenciones internacionales firmadas por el estado y las leyes internas.

Pero más allá de los textos jurídicos, la cuestión se centra en su aplicación a la sociedad.

En 1979 se deroga la Ley de Protección de la Familia aprobada en 1967, y reformada en 1974, negando así a las mujeres el derecho al divorcio y restableciendo el derecho de los hombres a divorciarse de manera unilateral. En 1974 el sha amplió la edad mínima legal de matri monio de mujeres de $\operatorname{los} 15$ a los 18 años. En 1980, la República islámica la rebajó a lo señalado por la sharía - 9 años-. Pero a lo largo del periodo, la edad media real de las mujeres para el matrimonio no ha hecho más que aumentar, aunque en algunos casos se den matrimonios precoces que desatan las iras de las feministas iraníes.

Existe, pues, una dinámica social que desdeña la legislación existente que acaba adaptándose a la fuerza a las realidades socio-econó micas, porque la sociedad iraní se ha modernizado.

En una sociedad más urbanizada, con un alto índice de alfabe tización, la mujer tiende a contraer matrimonio a una edad más tardía ${ }^{47}$, de tal forma que la edad de las mujeres para contraer matrimonio, al menos en el ámbito urbano, ha pasado de $\operatorname{los} 18$ a los 21 años, aunque el código de familia islámica haya rebajado la edad de matrimonio de las

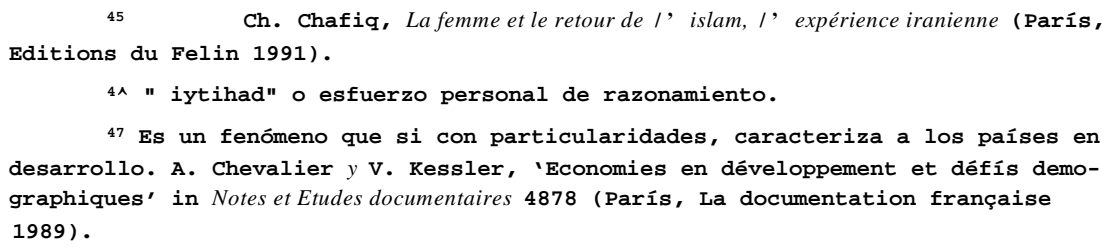




\section{Mujer y Poder en Irán Contemporáneo}

mujeres hasta los 9 años, lo que no tiene por qué significar que sea un precepto. También su incorporación al mundo del trabajo, sobre todo a partir de 1986, ha marcado pautas en su comportamiento reproductor ${ }^{48}$ que ha trastocado la estructura familiar tradicional, poniendo de mani fiesto el desajuste entre norma jurídica y realidad social.

Por otra parte, en su aplicación práctica, especialmente en aspectos como el divorcio, la poligamia o la custodia de los hijos, las mujeres comprometidas con el poder, exigieron enmiendas y modifica ciones a partir de la aplicación de versículos coránicos. De tal forma que cualquier divorcio debe ser dictado por un tribunal, y no simplemente por la triple fórmula de repudio como se hace en la "sharía" y que contempla la ley 1133; o si no existe contrato explícito en que figure el divorcio condicionado a la autorización de la primera esposa, o que no se haya previsto la concesión de una pensión alimenticia en caso de divorcio- se juzga válido el contrato tipo del matrimonio en que la mujer precise hasta cuando quiere estar con su hijo en caso de divorcio, y pueda exigir una suma de dinero tan elevada que haga imposible la ruptura del contrato; además consiguieron que las viudas de guerra pudieran conservar la custodia de sus hijos, Incluso que en caso de poligamia, la mujer pueda poner condiciones suplementarias en el momento del matrimonio.

La abogada Mehrenguiz Kar, en su columna jurídica "Aprendi zaje del derecho de las mujeres", informa sobre las precauciones jurídicas que se deben prever en el momento de hacer un contrato de matrimonio, puesto que la ley permite estipular condiciones específicas en dicho con trato, por lo que informa a las mujeres para que puedan preservarse de un sistema que les es desfavorable.

La gran avalancha de demandas judiciales sobre el matrimonio temporal, el divorcio, etc han llevado a flexibilizar las decisiones sobre el divorcio de la mujer y el acceso a cierta parte de los bienes del marido, en caso de que éste se divorcie, si en el contrato del matrimonio se deja fijado.

Las feministas luchan para que se reconozcan esas clausulas favorables y se inserten sistemáticamente en los contratos de matrimonio, sobre todo la que garantiza indemnizaciones o una pensión alimentaria en caso de divorcio.

48 F. Adelkah, 'Family Restructuring and Affirmation of the Individual in Muslim Countries: The Case of Iran' in G. Martin Mufloz. (ed). Islam. Modernism and the West (London, I.B. Tauris 1999) $191-207$.

\section{Faculdade de Letras Universidade de Coimbra}


Para enfrentarse a la arbitrariedad de los jueces, las mujeres han fundado un "Departamento para los Asuntos de las mujeres" que en 1996 consiguió la modificación de ciertos artículos de las leyes sobre la familia con el fin de proteger mejor los derechos de las mujeres casadas y divorciadas.

Es evidente que se ha iniciado una nueva etapa en las relacio nes entre mujer y Estado, caracterizada por un discurso pragmático de las mujeres, derivado de su confrontación con la realidad cotidiana en el ámbito jurídico.

\section{Para finalizar}

Desde los primeros años de la República islámica, las mujeres junto a los intelectuales, se van implicando en los debates jurídicos para lograr la revisión de las leyes actuales y para proponer otra interpretación del fiqh. El discurso sobre el fiqh representa también un conflicto entre generaciones.

Las mujeres iraníes se han constituido en una fuerza funda mental del cambio social, no sólo en la transformación de su propia situa ción sino también en el afianzamiento de los procesos democratizadores, tanto por su fuerza cuantitativa como por la aportación de su visión espe cífica al conjunto de los cambios sociales.

Protagonistas de la lucha que sobrepasa su sexo, las mujeres contribuyen a la evolución de la sociedad. El papel significativo jugado por las mujeres en el proceso de cambio y su contribución a la formula ción de nuevas reivindicaciones forman parte de las dimensiones estructu rales de la dinámica postislamista en Irán.

El camino de la emancipación y de la participación social de las mujeres, en condiciones de igualdad, es lento pero es un proceso imparable, y en Irán está teniendo unos efectos políticos y sociales esen ciales, pues no sólo ha conseguido unir con un mismo objetivo a islamistas y laicas, sino que junto a la labor de los intelectuales postislamistas, la confluencia entre diversas generaciones es cada vez mayor, $y$ se ha con vertido en una fuerza imparable con la que los inmovilistas que forman la "nomenklatura" tendrán que contar.

\section{Faculdade de Letras Universidade de Coimbra}

